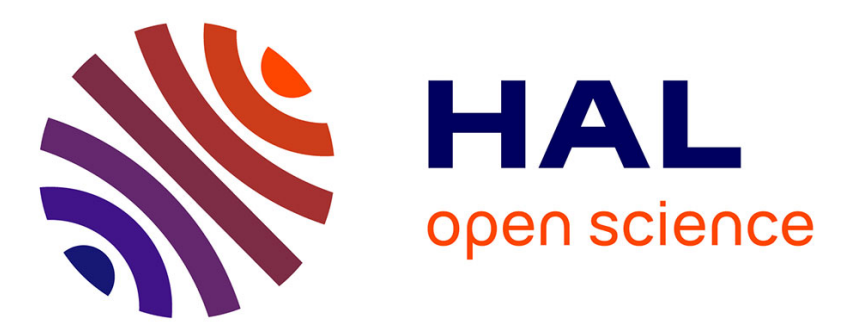

\title{
Subpicosecond all-optical logic gate: an application of the optical Stark effect
}

D. Hulin, A. Antonetti, M. Joffre, A. Migus, A. Mysyrowicz, N.

Peyghambarian, H.M. Gibbs

\section{- To cite this version:}

D. Hulin, A. Antonetti, M. Joffre, A. Migus, A. Mysyrowicz, et al.. Subpicosecond all-optical logic gate: an application of the optical Stark effect. Revue de Physique Appliquée, 1987, 22 (10), pp.12691271. 10.1051/rphysap:0198700220100126900 . jpa-00245676

\section{HAL Id: jpa-00245676 https://hal.science/jpa-00245676}

Submitted on 1 Jan 1987

HAL is a multi-disciplinary open access archive for the deposit and dissemination of scientific research documents, whether they are published or not. The documents may come from teaching and research institutions in France or abroad, or from public or private research centers.
L'archive ouverte pluridisciplinaire HAL, est destinée au dépôt et à la diffusion de documents scientifiques de niveau recherche, publiés ou non, émanant des établissements d'enseignement et de recherche français ou étrangers, des laboratoires publics ou privés. 
Classification

Physics Abstracts

$42.80 \mathrm{~S}-78.65-78.20 \mathrm{~J}$

\title{
Subpicosecond all-optical logic gate : an application of the optical Stark effect
}

\author{
D. Hulin $(*)$, A. Antonetti (*), M. Joffre $(*)$, A. Migus $(*)$, A. Mysyrowicz $\left({ }^{*}\right)$ \\ N. Peyghambarian $\left({ }^{+}\right)$and H. M. Gibbs $\left(^{+}\right)$ \\ (*) Laboratoire d'Optique Appliquée, Ecole Polytechnique-Ecole Nationale Supérieure des Techniques \\ Avancées, 91120 Palaiseau, France \\ $\left(^{+}\right)$Optical Sciences Center, University of Arizona, Tucson, Arizona 85721, U.S.A.
}

(Reçu le 20 novembre 1986, accepté le 9 janvier 1987)

\begin{abstract}
Résumé. - Nous avons démontré le fonctionnement à température ambiante d'une porte logique tout-optique avec des temps d'ouverture et de fermeture subpicoseconde, utilisant la même longueur d'onde pour chacun des faisceaux. Elle est constituée d'une structure à puits quantiques multiples (GaAs-GaAlAs) insérée dans un Fabry-Pérot de 1,3 $\mu \mathrm{m}$ d'épaisseur. Elle fonctionne grâce à un effet de champ purement optique (effet Stark optique).
\end{abstract}

\begin{abstract}
An all-optical logic gate is demonstrated to perform at room temperature with subpicosecond ON and OFF switching time using the same wavelength for both input beams. It consists of a GaAs-GaAlAs multiple quantum well structure inserted in a $1.3 \mu \mathrm{m}$ thick Fabry-Pérot and uses for its operation a purely optical field effect (optical Stark effect).
\end{abstract}

Optical bistable devices and logic gates are of current interest for their potential applications in future optical computers and signal processing $[1,2]$. Among them non-linear étalons are based on the non-linearity of an optical material placed between two partially reflecting mirrors. Semiconductors are attractive materials for such an application due to their large nonlinearity, room-temperature operation, small size and rapid response time. Taking advantage of a purely optical field effect, the socalled AC or optical Stark effect recently reported [3], we describe here the operation at room temperature of an all-optical logic gate with subpicosecond ON and OFF switching times.

Optical gating requires at least two input beams. For instance the transmission of a probe pulse can be controlled by the presence or absence of a « pump » beam used as a command. The probe transmission, which is the gate output, is adjusted by tunning its peak wavelength with respect to one of the FabryPérot (FP) resonance. The pump pulse changes the index of refraction of the material and shifts the Fabry-Pérot peaks. If in the absence of excitation the transmission is set to be high (probe wavelength tuned inside the FP peak), the gate output is forced now to the «low » state. By using more than two input beams various gating operations such as AND, OR, NOR, etc. have been demonstrated for étalons with bulk GaAs and GaAs-GaAlAs multiple quantum wells (MQWS).

In GaAs or MQWS samples the modification of the index of refraction in the transparency region originates from a change in the absorption spectrum. The excitonic resonance which gives rise to a strong absorption feature at the edge of the band to band absorption continuum can be easily modified by the presence of excited free carriers. The electron-hole plasma, among other effects, screens the Coulomb interaction between electrons and holes, preventing the further formation of excitons and leading to a decrease of the excitonic absorption. This modification induces in turn a change of the index of refraction in the transparency region (below the excitonic line). The amplitude of this index variation is (smoothly) wavelength dependent, the closest from the exciton the largest the induced change.

Several characteristics are of particular importance in the application to high-speed optical logic : time to make a logic decision (switch-on time), time required for the device to recover and be ready to 
make the next decision (recovery-time), energy required per logic decision (switching energy), heat dissipation, ability to switch the next device (cascadability), etc... In bulk or MQWS GaAs étalon, switch-on times shorter than one picosecond have already been reported [4], mostly limited by the rise time of the FP cavity. The switch-off time is usually in the nanosecond range, corresponding to the lifetime of the excited carriers in the semiconductor. Recently in thin étalon of GaAs, surface recombination has been used to get a recovery in tens of picoseconds, allowing a faster repetition rate [5]. Two different wavelengths are used in this kind of commutation, the first one having a good absorption to induce an appreciable index change at the second wavelength. This feature limits the possible use in cascadable processes. The operation of the optical gate by using the optical Stark effect provides an answer to these two problems : ultra-short recoverytime and identical input wavelengths.

The optical Stark effect consists in a high-energy shift and a bleaching of the exciton resonance during the irradiation of the sample with nonresonant optical pulses inside the energy gap $[3,6]$. This effect was first demonstrated in MQWS at low temperature but has also be observed in bulk GaAs or at room temperature since the excitonic structure is still present at $T=300 \mathrm{~K}$ in the MQWS absorption spectrum. The FP étalon is made of 100 alternating layers of $100 \AA \mathrm{GaAs}$ and $25 \AA \mathrm{AlGaAs}$ grown by molecular beam epitaxy with a $500 \AA$ AlAs etch-stop layer. A $200 \AA$ gold layer is deposited on each face, providing highly reflective interfaces $(10 \%$ transmission for one gold layer on glass at $800 \mathrm{~nm}$ ) and a measured finesse of 22 for the étalon. The very small thickness of the FP yields a large intermode separation of $65 \mathrm{~nm}$.

To demonstrate the use of our étalon as an ultrafast gate, we work with the classical pump and probe scheme. The primary pulse is provided by the output of a colliding pulse mode-locked dye laser at $615 \mathrm{~nm}$ amplified up to an energy of $1 \mathrm{~mJ}$ per pulse with a duration of less than $100 \mathrm{fs}$. This pulse is divided into two parts, each focused into a water cell to generate white pulses of similar duration. One of the continua is used as a weak probe. In the second continuum, a narrow-band interference filter $(7.5 \mathrm{~nm}$ width) centred in the near infrared $(0.8 \mu \mathrm{m})$ is inserted and the output is further amplified up to an energy of a few $\mu \mathrm{J}$, providing the pump pulse of $250 \mathrm{fs}$ duration. The polarizations of the pump and probe beams are set perpendicular. The delayed transmission of the probe is analysed through a spectrometer and an optical multichannel analyser (PAR OMA 3). The pump central wavelength is tuned inside the FP transmission peak, a situation imposed by the gate operation but also corresponding to a good penetration of the pump in the non- linear medium. The pump spectrum is broader than the FP mode to purposely avoid any bistability effect. The incident fluence is of the order of $1 \mathrm{pJ} / \mu \mathrm{m}^{2}$.

Figure 1 shows the time-resolved transmission of the Fabry-Pérot étalon in function of the delay with the pump pulse. The peak wavelength is just below the low energy side of the exciton in the MQWS at $T=150 \mathrm{~K}$. A shift of the transmission peak is observed during the excitation of the sample, the amplitude of which depends of the pump intensity.

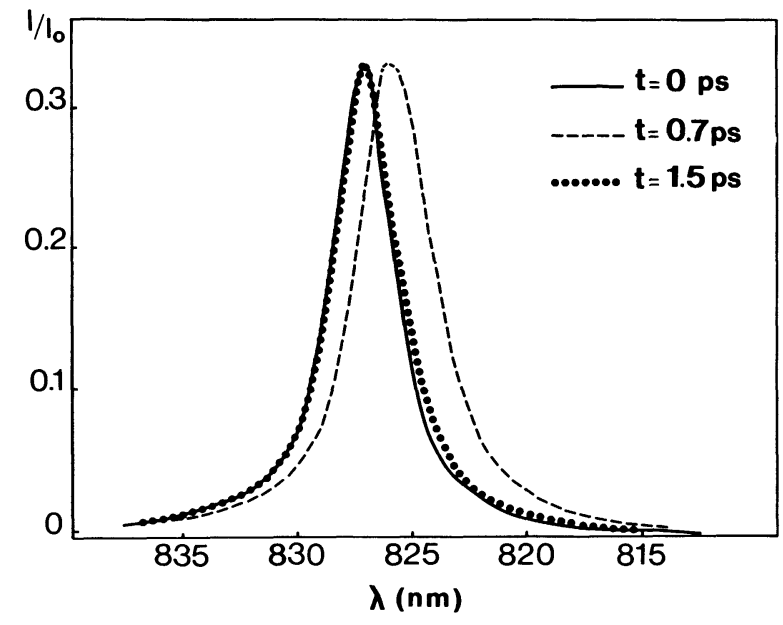

Fig. 1. - Time-resolved transmission of the Fabry-Pérot (FP) étalon at $T=150 \mathrm{~K}$ excited by a $827 \mathrm{~nm}$ pump pulse. The pump spectrum is broader than the FP transmission mode. The zero delay has been chosen $100 \mathrm{fs}$ before the onset of the peak displacement. The $0.7 \mathrm{ps}$ delay corresponds to the maximum effect.

At time $t=1.5 \mathrm{ps}$, the étalon peak has almost completely returned to its initial position, except for a small broadening on the high energy side. This long-lasting modification may be attributed to some carriers really excited in the sample (two-photon or phonon-assisted absorption) whereas the main effect corresponds to a virtual excitation of the carriers with no real population left after the pump pulse. The transmission on the low (high) energy side of the unperturbed FP peak exhibits a decrease (increase) and a recovery in less than $1.5 \mathrm{ps}$ with an amplitude of $2 / 1$ at $828.3 \mathrm{~nm}(1 / 4$ at $823.5 \mathrm{~nm})$.

Although this gate can operate at room temperature, the first demonstration [7] was reported at $T=150 \mathrm{~K}$ because in our sample the detuning between the exciton and the FP peak is large (in excess of $40 \mathrm{~nm}$ ) at room temperature. Since the amplitude of index variation depends on this detuning, a better efficiency is obtained by setting the FP mode close to the exciton line. In order to shift the excitonic resonance, the crystal was cooled down to $150 \mathrm{~K}$. We present here the operation of this gate at room temperature. Figure 2 shows the transmis- 


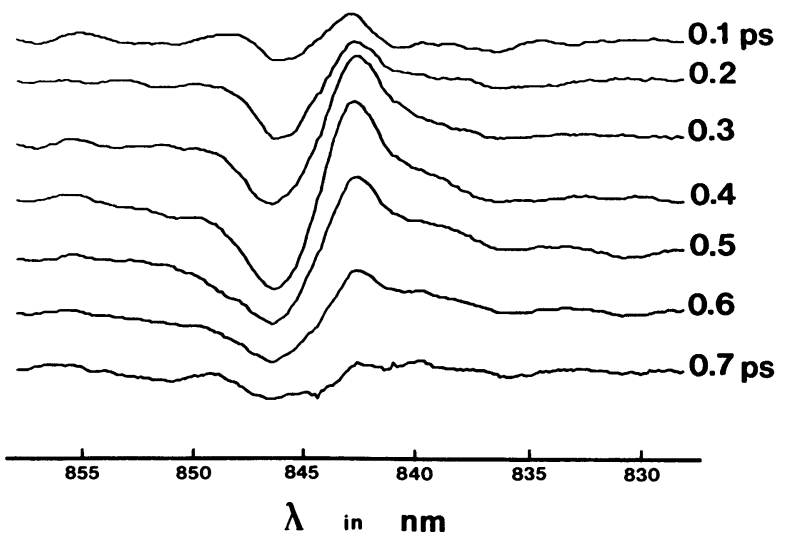

Fig. 2. - Time-resolved transmission differences of the FP étalon at room temperature. The excitation peak wavelength is at $844 \mathrm{~nm}$ with a spectrum broader than the FP mode. The zero delay has been set just before any change in the transmission.

sion difference with respect to the unexcited spectrum in function of the delay between the pump and probe pulses. Since the time interval between two curves is $100 \mathrm{fs}$, the overall operation of the gate lasts less than $0.8 \mathrm{ps}$. The efficiency is reduced by comparison with the case at $150 \mathrm{~K}$ due to the larger detuning with the excitonic resonance, but the behaviour is identical. By adjusting the thickness of the étalon during the fabrication process, it will be possible to increase markedly this efficiency.

The requirement of low fluence is not completely fulfilled in our experiment but the energy dissipated in the medium is very small and does not lead to an appreciable rise of the temperature since the medium is essentially transparent to the pump pulse. Furthermore, an étalon with a greater finesse would require less power to commute, even at the expense of some time lengthening. To summarize, we have reported the operation of an all-optical gate at roomtemperature, with subpicosecond ON and OFF response time and working with the same wavelength for both inputs (pump and probe in our case). The origin of the ultrashort recovery is tied to the recently reported optical Stark effect which induces large changes in the excitonic features only during the presence of the electromagnetic field of the pump pulse.

We are very grateful to $W$. T. Masselink and $H$. Morkoc of the University of Illinois at UrbanaChampaign for the elaboration of the device.

\section{References}

[1] GIBBS, H. M., Optical Bistability : Controlling Light with Light (Academic Press) 1985.

[2] Gibbs, H. M., Mandel, P., Peyghambarian, N. and SMITH, S. D., Eds., Optical Bistability III (Springer Verlag, Berlin) 1986.

[3] Mysyrowicz, A., Hulin, D., Antonetti, A., MigUS, A., MASSElinK, W. T. and MORKOC,, H., Phys. Rev. Lett. 56 (1986) 2748.

[4] Migus, A., ANtonetti, A., Hulin, D., Mysyrowicz, A., Gibbs, H. M., PeyghamBarian, N. and Jewell, J. L., Appl. Phys. Lett. 46 (1985) 70.
[5] Lee, Y. H., Warren, M., Olbright, G. R., Gibbs, H. M., Peyghambarian, N., Venkatesan, T., Smith, J. S. and Yariv, A., Appl. Phys. Lett. 48 (1986) 754.

[6] Von Lehmen, A., Zucker, J. E., Heritage, J. P. and Chemla, D. S., Opt. Lett. 11 (1986) 609.

[7] Hulin, D., Mysyrowicz, A., Antonetti, A., Migus, A., MasselinK, W. T., MoRKoç, H., Gibis, H. M. and Peyghambarian, N., Appl. Phys. Lett. 49 (1986) 749. 